\title{
PRESSUPOSTOS TEÓRICOS PARA O ESTUDO DE POLÍTICA CRIMINAL: PROPOSTAS PARA UMA ANÁLISE TIPOLÓGICA
}

\section{André Luís Callegarl}

Doutor e pós-doutor em Direito Penal pela Universidad Autónoma de Madrid. Professor da graduação e pós-graduação (mestrado e doutorado) em Direito da Universidade do Vale do Rio dos Sinos (UNISINOS). Pesquisador do CNPq.

Clara Moura Masiero

Doutoranda em Direito pela Universidade do Vale do Rio dos Sinos (UNISINOS). Bolsista CAPES/PROEX. Mestre em Ciências Criminais pela Pontifícia Universidade Católica do Rio Grande do Sul (PUCRS). Professora do curso de Direito da Estácio/FARGS.

\section{Resumo}

Este artigo tem por objetivo apresentar pressupostos teóricos para o estudo de política criminal. Para tanto, expóe duas propostas de modelos de análises de tendências político-criminais: uma desenvolvida por David Garland (em "The culture of control", 2001), que utiliza as categorias político-criminais "moderação" e "punitivismo"; e outra desenvolvida por José Luís Díez Ripollés (em "Direito penal y política criminal”, 2013), que se contrapóe à primeira e propóe, por outro lado, a utilizaçáo das categorias de política criminal "inclusiva socialmente" e "exclusiva socialmente". Com isso, pretende-se possibilitar o desenvolvimento de análises comparativas rigorosas entre as políticas criminais de Estados diferentes ou, até mesmo, de um mesmo Estado no decorrer do tempo.

\section{Palavras-chave}

Política criminal; Punitivismo; Moderação; Inclusão social; Exclusão social.

\section{Resumen}

Este artículo tiene como objeto la presentación de marcos teóricos para el estudio de la política criminal. Para ello expone dos propuestas de modelos de análisis de tendencias político-criminales: una que desarrolló David Garland (en "The culture of control”, 2001), que utiliza las categorías político-criminales "moderación” y "punitivismo"; y otra que desarrolló José Luís Díez Ripollés (en “Derecho penal y politica criminal”, 2013), que se contrapone a la primera y propone, por otro lado, la utilización de las categorías de política 
criminal "inclusiva socialmente" y "exclusiva socialmente". Con ello se busca posibilitar el desarrollo de análisis comparativos rigurosos entre las políticas criminales de Estados diferente o incluso de un mismo Estado en el transcurso del tiempo.

\section{Palabras clave}

Política criminal; Punitivismo; Moderación; Inclusión social; Exclusión social.

\section{Introdução}

As respostas políticas diante do problema do crime devem ter como base uma sólida política criminal, ancorada em princípios e recomendaçóes, fruto dos resultados que apresentem novas ou antigas propostas do direito penal, das revelaçóes empíricas e dos avanços e descobertas da criminologia. As discussóes sobre temas da criminologia e do direito penal, entretanto, na maior parte das vezes, são repletas de informaçóes náo comprovadas empiricamente. Além disso, não há o hábito de avaliação das reformas legislativas aprovadas e das políticas colocadas em prática, o que acarreta no desconhecimento dos seus reais efeitos nos sistemas social e jurídico; o que ocorre a despeito da afirmação de que "mais importante que a interpretação das leis é analisar o processo de aplicação das mesmas à realidade social; processo tenso, conflitivo e problemático" (GARCÍA-PABLOS DE MOLINA, 2006, p. 97).

Tendo em vista essas constatações, busca-se, com este trabalho, estabelecer pressupostos teóricos para análises rigorosas a respeito de política criminal, sobretudo em âmbito comparativo, isto é, seja para comparar as políticas criminais implantadas por diferentes Estados, seja em relação à política criminal de um Estado no decorrer do tempo. Esse tipo de análise permite conceber as respostas tomadas em relação ao crime como escolhas políticas não inevitáveis e que podem ser de diversas maneiras.

Os pressupostos aqui apresentados têm como base teórica os modelos analíticos propostos por David Garland (2008) e por José Luís Díez Ripollés (2013).

David Garland desenvolve um estudo sobre o campo do controle do crime dos Estados Unidos da América e da Grã-Bretanha, em uma perspectiva histórico-social. Com isso, identifica a passagem do previdenciarismo penal, presente durante o que o autor concebe como período modernista penal, para o populismo punitivo, característico do que o autor chama de pós-modernismo penal. Além disso, Garland revela as tendências político-criminais atuais presentes, em maior ou menor medida, no interior desse paradigma populista nos EUA e na Grã-Bretanha, mas que, por avaliação do autor, podem também ser percebidas nos demais países ocidentais: respostas adaptativas, denegatórias e simbólicas. 
José Luís Díez Ripollés, por sua vez, contesta as categorias propostas por Garland e concebe outro modelo analítico, cuja perspectiva de análise passa a ser a comparação entre políticas criminais inclusivas socialmente e exclusivas socialmente. Isto é, o autor propóe que se analise os efeitos sociais gerados por uma dada política criminal e náo mais táo somente se ela é mais punitiva ou moderada.

A relevância deste trabalho está em proporcionar perspectivas de análise políticocriminal neste momento histórico em que as políticas criminais passam, mais uma vez, pela adequação às transformaçóes da sociedade, do Estado e da criminalidade, com o que modificaçôes conjunturais mais ou menos profundas no sistema penal vêm ocorrendo. Advém, assim, a necessidade de compreender e dar ênfase à estrutura real das novas formas e dinâmicas do Direito penal e da política criminal que estấo passando por processos de transformação, por meio da sociologia jurídica; em vez de procurar conservar os pressupostos iluministas do sistema de controle tradicional e, até mesmo, da dogmática penal.

Intenta-se, em última análise, para além de um diagnóstico, contribuir para a concretização de uma política criminal democrática e integrada, que leve em consideraçấo, não só a repressão, mas, sobretudo, a prevenção e a inclusáo social, e que procure avançar no desdobramento de novos instrumentos regulativos de controle.

\section{Modelo Analítico Proposto por David Garland}

Um dos mais influentes estudos a respeito de tendências político-criminais é o realizado por David Garland, publicado em 2001 sob o título "The culture of control"1. Esse estudo tem por objetivo apresentar as mudanças ocorridas na política criminal (ou no campo do controle do crime, como prefere o autor) dos Estados Unidos da América (EUA) e da Grã-Bretanha quando da passagem da modernidade penal (do final do século XIX até 1970) para a pós-modernidade (de 1980 em diante).

Garland fundamentou sua análise político-criminal nos fatores históricos e nas mudanças sociais que influenciaram o campo. Isso porque ele parte do pressuposto de que "o reconfigurado campo do controle do crime é resultado de escolhas políticas e de decisóes administrativas, ambas assentadas sobre uma nova estrutura de relaçóes sociais e informadas por um novo padrão de sensibilidades culturais" (GARLAND, 2008, p. 48). A importância da abordagem histórico-comparativa é a de desnaturalizar as atuais escolhas político-criminais, pois pode demonstrar que num passado próximo havia outro modo de controle do crime.

1 Versão brasileira: A Cultura do Controle: crime e ordem social na sociedade contemporânea. Rio de Janeiro: Revan, 2008. 
Para diferenciar esses dois modos diferentes de lidar com o controle do crime, Garland concebe duas amplas categorias de política criminal: o "previdenciarismo penal" e o “populismo punitivo". A primeira categoria é utilizada pelo autor para denominar a política criminal vigente no final do século XIX até 1970 e a segunda, o período subsequente, isto é, de 1980 até hoje.

Segundo descreve o autor, a modernização do controle penal e da justiça criminal, que advém, por sua vez, em oposição aos modos tradicionais e privados de controle do crime, ocorre por meio de processos híbridos de diferenciação, estatização, burocratização e profissionalização da polícia, do processo e da penalização. Pode-se dizer, então, que a estrutura penal moderna combinava "o legalismo liberal do devido processo legal e da punição proporcional com um compromisso correcionalista de reabilitação, bem-estar e o saber criminológico especializado" (GARLAND, 2008, p. 93).

Este modo de controle do crime parte, segundo o autor, de dois axiomas: (i) "a reforma social, juntamente com a prosperidade econômica, acabariam por reduzir a frequência do crime"; e (ii) "o Estado é responsável por cuidar dos criminosos, bem como por sua punição e seu controle" (GARLAND, 2008, p. 110). Tem-se, com isso, um novo estilo de exercício do poder e um novo tipo de autoridade social: os especialistas sociais.

Esse estilo, amparado no saber especializado e nas técnicas de regulação, trazia uma combinação de humanitarismo e motivaçóes utilitárias. É o que o autor chama de "previdenciarismo penal". Isso porque são compromissos do modernismo: a fé na razão científica, a perfeição do homem, o racionalismo tradicional, a utilização de medidas individualizadas, corretivas, cuidadosamente adaptadas ao caso concreto, assim como tratamentos. Com isso, expressões explícitas de punitivismo se fizeram cada vez mais escassas.

Apesar disso, adverte o autor para o fato de que "obviamente, os sentimentos punitivos não desapareceram. Foram, pelo contrário, reprimidos, empurrados para a sombra, considerados embaraçosos em circuitos ilustrados" (GARLAND, 2008, p. 114). Com efeito, o controle governamental do crime continuava a focar mais na punição reativa de criminosos do que na prevenção social do crime; intervindo, pois, depois que o mal estiver feito, tratando das consequências e não das causas (GARLAND, 2008).

Na metade da década de 1970, o apoio ao previdenciarismo penal começou a ruir, em razão da pressão feita por um ataque continuado a suas premissas e práticas (críticas ao correcionalismo, às penas indeterminadas, ao tratamento individualizado). Movimento este que, inicialmente, visava a ampliar os direitos dos presos, minimizar o encarceramento, restringir o poder estatal e a proscrever a prisão cautelar; mas que, como se verá, desaguou em políticas que postulavam exatamente o contrário. A partir de entâo houve uma rápida e marcante guinada na filosofia e nos ideais penais, culminando no que o autor chamará de "populismo punitivo". (GARLAND, 2008). 
O colapso da fé no correcionalismo iniciou uma onda de desmoralização, que minou a credibilidade das instituiçóes do controle do crime, alimentada, ainda, pelo grande aumento nas taxas de criminalidade, nos anos 1970 e 1980. E ainda gerou o efeito de unir a esquerda, a direita, o centro, os liberais, os radicais e os conservadores na negação ao correcionalismo e à reabilitação (GARLAND, 2008).

Claro que Garland traz todo um conjunto mudanças sociais que ajudaram a desencadear este movimento de alteração político-criminal. As forças transformadoras, segundo o autor, podem ser divididas em dois grupos: (i) chegada da pós-modernidade: transformou algumas das condiçóes sociais e políticas sobre as quais se assentava o campo do controle do crime moderno, trazendo novos problemas de crime e insegurança; (ii) políticas do pós-previdenciarismo: produziu um novo conjunto dominante de política, opositor ao previdenciarismo e dos ideais sociais e culturais, decorrente da emergência de novas sensibilidades (medo, indigninação e hostilidade). Escolhas políticas, essas, adverte o autor, que "não foram em absoluto inevitáveis" (GARLAND, 2008, p. 183).

Assim, a partir da crise do previdenciarismo penal, "um dilúvio de novos programas e de iniciativas políticas tomou a cena, propondo novos objetivos institucionais, novos regimes penitenciários e de policiamento e novas concepçóes sobre o problema do crime e sua solução" (GARLAND, 2008, p. 241). Por isso, pode-se dizer que o campo do controle do crime, nos anos 1980 e 1990, testemunhou um processo constante de fermentaçáo e reforma.

A verdade é que, nesse período, configurou-se um novo dilema político, composto por dois fatos sociais: (i) a normalidade de altas taxas de criminalidade, isto é, o crime não é mais concebido como um fenômeno anormal, mas como uma possibilidade sempre presente; e (ii) as reconhecidas limitaçóes do Estado de justiça criminal (baixa efetividade), isto é, uma atitude nova e pessimista de que "nada funciona”. A partir desse dilema é que as respostas do crime tem sido configuradas.

O resultado, segundo Garland:

É uma série de políticas esquizofrênicas, que parecem conflitar entre si. Por um lado, tem-se tentado enfrentar o dilema e procurado desenvolver novas estratégicas pragmáticas, adaptadas a ele: através de reformas institucionais tendentes a superar os limites do Estado de justiça criminal, ou através de acomodaçôes que reconheçam estas limitações e as trabalhem (GARLAND, 2008, p. 249).

Por outro lado, há reaçóes politizadas em outros dois sentidos: um que nega abertamente o dilema e reafirma o velho mito do Estado soberano e seu poder punitivo pleno; e outro que abandona a ação racional, instrumental, descrito pelo autor como atuação simbólica. Nesse momento, então, Garland fornece um modelo analítico de política 
criminal, ao identificar três tipos de respostas com as quais os Estados estão conformando suas políticas criminais na pós-modernidade: (i) respostas de adaptação; (ii) respostas de negação; e (iii) respostas simbólicas.

As respostas de adaptação, que eram bastante utilizadas antes da virada dos paradigmas moderno ao pós-moderno, caracterizam-se por decisóes administrativas sequenciais e de baixa visibilidade, que visam a inserir o controle social no tecido social da vida cotidiana, reduzir os efeitos criminógenos das transaçóes econômicas, proteger vítimas recorrentes. $\mathrm{O}$ autor elenca as seis principais formas de adaptação: (i) racionalização da justiça; (ii) comercialização da justiça; (iii) restrição da criminalização; (iv) redefinição do êxito; $(v)$ concentração sobre as consequências; e $(v i)$ redistribuiçãa das responsabilidades pelo controle do crime.

Paralelamente a essas respostas adaptativas, a máquina política do Estado "se engajou numa espiral de fuga e negação de forma quase histérica, no sentido clínico do termo" (GARLAND, 2008, p. 279). Ou seja, em vez de reconhecer os limites do Estado e procurar adaptar-se a eles, a agenda política consistia em restaurar a confiança pública na justiça criminal, afirmando os valores da disciplina moral, da responsabilidade individual e do respeito pela autoridade. Isto é, na política criminal o imperativo residia na reimposição de controle, normalmente por meio de medidas punitivas.

Segundo Garland, as respostas de negação desprezam "as evidências de que o crime não reage rapidamente a puniçóes duras, a novos poderes policiais ou ao maior recurso ao encarceramento, as legislaturas têm recorrentemente adotado uma postura punitiva de 'lei e ordem'” (GARLAND, 2008, p. 280). Negam, assim, as limitações já reconhecidas por suas próprias administraçóes e, ao invés de adaptação, procedem à reafirmação e à expansão do controle penal.

A atuação simbólica, por sua vez, significa, para o autor, uma atuação impulsiva e irrefletida, que evita o reconhecimento realista de problemas subjacentes. São medidas instituídas para:

Simbolizarem açóes expressivas, catárticas, de maneira a censurar o crime futuro, conquanto ruidosamente decantada, é frequentemente duvidosa e, em todo caso, menos importante do que sua habilidade imediata de representar o sentimento público, de proporcionar respostas instantâneas, de funcionar como medida retaliadora cuja virtude é sua própria existência (GARLAND, 2008, p. 282).

Esse tipo de resposta é tipicamente aprovada no calor da indignação popular frente a crimes violentos marcantes. Garland traz como exemplos de medidas simbólicas as seguintes legislações aprovadas nos anos 1990 nos EUA: as leis de Megan, Three Strikes, estatutos de predadores sexuais, reintrodução das prisóes para crianças, registros de 
pedófilos, penas privativas de liberdade obrigatórias, reintrodução do acorrentamento coletivo de presos, instituiçóes de tratamento, puniçóes vexatórias e tentativas de reviver as penas corporais.

São leis desprovidas de racionalidade legislativa, que funcionam mais como gestos retaliadores alinhados ao senso comum. Segundo percepção do autor, ao que tudo indica, "a disposição de aplicar penas severas a criminosos condenados compensa, magicamente, o fracasso em prover segurança para a população em geral” (GARLAND, 2008, p. 283).

Enfim, as mudanças estruturais desencadeadas a partir da crise do previdenciarismo penal e da passagem da modernidade para a pós-modernidade, conformou a política criminal denominada por Garland de "populismo punitivo". A tabela abaixo procura ilustrar as modificações geradas por essa mudança de paradigmas político-criminais.

\section{Tabela 1 - Sinais da Mudança}

\begin{tabular}{|c|c|}
\hline $\begin{array}{l}\text { FINAL DO SEC. XIX - XX } \\
\text { (Até 1970) }\end{array}$ & 1980/1990 E SÉCULO XXI \\
\hline Previdenciarismo penal & Populismo punitivo \\
\hline Reabilitação & $\begin{array}{c}\text { Retribuição/neutralizaçáo/gerenciamento } \\
\text { de riscos }\end{array}$ \\
\hline $\begin{array}{c}\text { Rechaça pensamento retributivista e } \\
\text { punitivo }\end{array}$ & $\begin{array}{l}\text { Explicita pensamento punitivo e } \\
\text { retributivista }\end{array}$ \\
\hline Racionalização da justiça criminal & Dramatização da justiça criminal \\
\hline $\begin{array}{l}\text { Vítima como um cidadão } \\
\text { desafortunado, atingido pelo crime, } \\
\text { cujo interesse se subsume ao interesse } \\
\text { público }\end{array}$ & $\begin{array}{c}\text { Vítima é personagem representativo, cuja } \\
\text { experiência é projetada para o comum } \\
\text { e o coletivo, em vez de ser considerada } \\
\text { individual e atípica. }\end{array}$ \\
\hline $\begin{array}{l}\text { Proteção do público raramente servia de } \\
\text { motivação para a elaboração de políticas } \\
\text { públicas }\end{array}$ & $\begin{array}{l}\text { Proteger o público se tornou o tema } \\
\text { dominante da política criminal }\end{array}$ \\
\hline Interesse pela opinião de especialistas & $\begin{array}{l}\text { Interesse pela opinião pública: } \\
\text { politizaçáo, eleitoralização e populismo }\end{array}$ \\
\hline "A prisão não funciona" & "A prisão funciona" \\
\hline $\begin{array}{l}\text { Pensamento criminológico passava por } \\
\text { teorias psicológicas da anormalidade e } \\
\text { teorias sociológicas (anomia, subcultura } \\
\text { e rotulaçáo): crime era um desvio da } \\
\text { conduta normal }\end{array}$ & $\begin{array}{l}\text { Teorias do controle/criminologia da vida } \\
\text { cotidiana: escolha racional, atividade } \\
\text { rotineira, crime como oportunidade e } \\
\text { prevençáo situacional do crime }\end{array}$ \\
\hline
\end{tabular}




\begin{tabular}{|c|c|}
\hline $\begin{array}{l}\text { FINAL DO SEC. XIX - XX } \\
\text { (Até 1970) }\end{array}$ & 1980/1990 E SÉCULO XXI \\
\hline $\mathrm{X}$ & $\begin{array}{l}\text { Expansão da infraestrutura da prevenção } \\
\text { do crime e da segurança da comunidade }\end{array}$ \\
\hline $\mathrm{X}$ & Incremento da segurança privada \\
\hline $\mathrm{X}$ & $\begin{array}{l}\text { Novos estilos de gerência e de rotinas de } \\
\text { trabalho }\end{array}$ \\
\hline $\mathrm{X}$ & Perpétua sensação de crise \\
\hline $\begin{array}{l}\text { Arcabouço intelectual definido: } \\
\text { estruturas erigidas em sua forma liberal } \\
\text { clássica + orientaçáo correcionalista }\end{array}$ & $\mathrm{X}$ \\
\hline
\end{tabular}

Fonte: MASIERO; CHIES-SANTOS (2014).

Nota: A partir de GARLAND, 2008.

A importância deste estudo de Garland se dá, sobretudo, porque essa mudança ocorreu em todas as culturas, ainda que, segundo o autor, esteja mais dominante nos EUA e na Grā-Bretanha: "nossa cultura cívica se torna cada vez menos tolerante e inclusiva, cada vez menos capaz de confiar" (GARLAND, 2008, p. 415).

\section{Modelo Analítico Proposto por José Luis Díez Ripollés}

José Luis Díez Ripollés (2013), na publicação "Direito penal y política criminal", opóe-se ao modelo analítico de Garland e propóe outra tipologia político-criminal, na medida em que entende que a hipótese de Garland de que todos os países ocidentais estariam caminhando para um endurecimento generalizado do sistema penal e, consequentemente, a uma política criminal mais rigorosa, não estaria se confirmando na realidade. Díez Ripollés (2013), inclusive, elenca alguns estudos ${ }^{2}$ que pretendem demonstrar que nos países ocidentais, na verdade, conviviam e convivem modelos e tendências políticocriminais distintos, inclusive contrapostos.

O enfoque do autor parte da análise da Europa Ocidental e procura demonstrar o grau de divergência político-criminal entre esses países e os EUA e a Grã-Bretanha, mas não é só: apesar de ter como marco analítico a Espanha, sua ideia é desenvolver uma tipologia

2 "Nelken (2005): 218-219; (2010): 10, 57-59; Brown, D. (2005): 29, 35-42; Hinds (2005): 59-60; Moore/ Hannah-Moffat (2005): 86-88; Meyer/O’Malley (2005): 201-203, 213-214; Roché (2007): 472, 476, 494-504, 540-545; Tonry (2007): 1-2, 38-40; Snacken (2007): 207-209; Webster/Doob (2007): 301302; Lappi-Seppälä (2008): 313-314” apud DÍEZ RIPOLLÉS, 2013, p. 140. 
que torne possível avaliar as políticas criminais de todos os países, sobretudo em uma perspectiva comparativa. Para tanto, inicia seu estudo com uma análise preliminar teórica a respeito das tendências político-criminais gerais, para só depois propor um estudo empírico e comparativo entre as tendências específicas adotadas pelos Estados.

Assim como Garland (2008), Díez Ripollés (2013) também identifica uma forte politização das políticas criminais nacionais. A propósito, ele destaca três fenômenos nessa direção.

O primeiro fenômeno diz respeito ao fato de que a política criminal deixou de refletir as diferenças ideológicas, por exemplo, entre direita e esquerda. Segundo o autor, "somente restam indícios de antigos signos distintivos, como uma maior resistência à estigmatização do delinquente na esquerda, ou as ocasionais reticências da direita sobre intervençóes punitivas excessivamente invasivas da esfera pessoal” (DÍEZ RIPOLLÉS, 2013, p. 140-1, tradução dos autores).

O segundo fenômeno está ligado com a demonstração de que a agenda políticocriminal é determinada e configurada predominantemente pelos partidos políticos e não pelas autênticas demandas sociais ou, principalmente, pela realidade social a ser confrontada. Essa situação corrobora para a conclusão do autor de que "na configuração da política criminal tenham mais presença decisóes valorativas ou ideológicas que consideraçóes utilitárias ou de eficácia” (DÍEZ RIPOLLÉS, 2013).

E o terceiro fenômeno aponta para o fato de que as práticas político-criminais estrangeiras, ou as obrigaçóes internacionais, estão influenciando cada vez mais nas decisóes nacionais sobre prevenção ou redução da delinquência, isto é, sobre a política criminal nacional. Segundo o autor, "os modelos estrangeiros mais prestigiados, entre os quais se destaca entre muitos países o dos Estados Unidos, penetram difusamente nos centros de decisão político-criminal; esta interação é positiva e justifica os estudos de política criminal comparada" (DÍEZ RIPOLLÉS, 2013, p. 142).

Para além desse diagnóstico genérico a respeito das tendências das políticas criminais, Díez Ripollés adverte para a necessidade de criação de um modelo analítico para possibilitar uma análise rígida das políticas criminais nacionais, de modo a poder compará-las. Díez Ripollés (2013) elenca, então, alguns pressupostos teóricos e metodológicos necessários para uma correta análise de estratégias político-criminais nacionais: (i) a política criminal insere-se dentro do conjunto de políticas públicas; (ii) a finalidade de toda política criminal é prevenir a delinquência dentro de parâmetros socialmente aceitáveis; (iii) a colocação em prática de qualquer política criminal exige que se escolham, elaborem e implementem objetivos específicos que sejam coerentes com essa finalidade.

Ainda, diz o autor que para descrever uma política criminal nacional é imprescindível que sejam elaborados indicadores confiáveis, isto é, “com capacidade para identificar 
traços característicos de seu funcionamento e para verificar os avanços e retrocessos na obtenção de seus objetivos" (DÍEZ RIPOLLÉS, 2013, p. 143).

O modelo analítico proposto por Díez Ripollés (2013) — diferentemente do proposto por Garland (2008) — não gira em torno do grau de moderação punitiva das políticas criminais nacionais, toma como referência, outrossim, a capacidade do correspondente sistema penal nacional para minimizar a exclusão social dos que entram em conflito com a lei penal. Isso supóe avaliar as políticas criminais segundo suas capacidades de permitir a "aquisição, recuperação, consolidação ou, ao menos, a não deterioração de um aceitável nível de inclusão social dos suspeitos e dos delinquentes" (DÍEZ RIPOLLÉS, 2013, p. 146, tradução dos autores).

Com isso, Díez Ripollés cria duas novas categorias para a análise político-criminal: a dimensão inclusiva e a dimensão exclusiva, as quais refletem aproximaçóes contrapostas ao objetivo de prevenir a delinquência de pessoas propensas a entrar em conflito com a lei penal. Senão, vejamos:

O enfoque inclusivo pretende assegurar que o suspeito ou delinquente se encontre, depois de seu contato com os órgáos de controle penal, em iguais ou melhores condiçôes individuais e sociais para desenvolver voluntariamente uma vida em conformidade com a lei. O enfoque exclusivo quer garantir que o suspeito ou delinquente se encontre, depois de seu contato com os órgãos de controle penal, em condições individuais e sociais nas quais lhe resulte mais difícil infringir a lei ou evitar ser descoberto (DÍEZ RIPOLLÉS, 2013, p. 146, tradução dos autores).

Esta proposta fundamenta-se em duas hipóteses essenciais e correlacionadas: $(i)$ "a manutenção de um certo nível de inclusão social de suspeitos, delinquentes e ex-delinquentes é uma das mais eficazes estratégias para a prevenção da delinquência” (DÍEZ RIPOLLÉS, 2013, p. 146, tradução dos autores); (ii) "a produção ou aprofundamento da exclusão social de suspeitos, delinquentes e ex-delinquentes pelas instituiçóes de controle penal gera maior delinquência a médio e longo prazo" (DÍEZ RIPOLLÉS, 2013, p. 146, tradução dos autores).

Pode-se supor que uma política criminal inclusiva socialmente seria necessariamente uma política criminal moderada, enquanto que a exclusiva seria sempre a mais punitiva; entretanto, o autor refuta essa hipótese, na medida em que não estão necessariamente presentes nas mesmas sociedades. É que as sociedades situadas mais próximas da ponta da inclusão do que da exclusão social, por exemplo, apesar de serem mais sensíveis à igualdade social e à proscrição de condutas vantajosas, tendem a desenvolver processos de criminalização primária de comportamentos dos setores sociais poderosos em maior 
medida do que as próprias políticas criminais mais exclusivas. Logo, seriam, dentro deste âmbito de intervenção penal em específico, mais punitivas do que as sociedades excludentes socialmente. Ainda,

Sociedades consideradas muito inclusivas podem desenhar programas de criminalização primária muito extensivos, com a finalidade de prevenir processos de desorganização social que possam ameaçar sua capacidade integradora: é, sem dúvida, o caso dos países nórdicos a respeito de sua política de persecução do tráfico e consumo de drogas, e quiçá esteja acontecendo já em relação à persecução da prostituição e pornografia infantil. Isso é compatível com uma prática moderada e de bem-estar no momento de aplicar as correspondentes reaçóes penais (DÍEZ RIPOLLÉS, 2013, p. 150, tradução dos autores).

Mais uma razão, portanto, para a utilização das categorias "inclusivas" e "exclusivas", em detrimento das até então inquestionáveis "punitivas" e "moderadas".

A ideia do autor é construir uma linha comparativa em que, em um polo, teríamos um Estado com a política criminal mais inclusiva socialmente, e em outro polo, o Estado com a política criminal mais exclusiva socialmente, enquanto os demais países ficariam localizados mais para um lado ou mais para outro, a depender do grau de inclusividade ou exclusividade social.

Para determinar esse grau em que os diferentes sistema de justiça criminal se encontram, Díez Ripollés ressalta que se tem que identificar as regras e práticas punitivas e, a partir daí, desvelar que efeitos sáo produzidos sobre as pessoas envolvidas, isto é, se geram inclusão ou exclusão social. Mas, para uma análise comparativa rigorosa, o autor vai além e sugere a transformação dessas regras e práticas em indicadores, o que permitirá proceder às comparaçóes.

Para construir essa linha tipológica, Díez Ripollés parte de duas hipóteses: a primeira diz respeito aos indicadores e a segunda, aos países que servirão de paradigma de um polo ou de outro.

Quanto aos indicadores, o autor sugere nove indicadores-chave, aos quais outros indicadores estão agrupados, configurando, ao todo, vinte e cinco indicadores. Esses indicadores têm, segundo o autor, as qualidades necessárias para revelar os efeitos socialmente inclusivos ou exclusivos de um sistema criminal, assim como para caracterizar comparativamente o respectivo sistema entre as dimensóes contrapostas (DÍEZ RIPOLLÉS, 2013).

Os vinte e cinco indicadores, agrupados em torno dos indicadores-chave, estão esquematicamente formulados no gráfico que segue: 


\section{Gráfico 1 - Indicadores}

\begin{tabular}{|c|c|}
\hline 1. Controle de espaços públicos & $\begin{array}{l}\text { - Urbanizações fechadas } \\
\text { - Vídeovigilância } \\
\text { - Proibições urbanas de acesso }\end{array}$ \\
\hline 2. Garantias penais & $\begin{array}{l}\text { - Enfraquecimento de garantias processuais } \\
\text { - Obstaculização ou restrição de recursos judiciais }\end{array}$ \\
\hline $\begin{array}{l}\text { 3. Sistema de determinação da pena } \\
\text { e sistema de sanções }\end{array}$ & $\begin{array}{l}\text { - Discricionariedade judicial } \\
\text { - Leis agravadas de reincidência } \\
\text { - Uso extensivo da prisão } \\
\text { - Penas alternativas à prisão } \\
\text { - Contreleseletrênices }\end{array}$ \\
\hline 4. Penas máximas & $\begin{array}{l}\text { - Pena de morte } \\
\text { - Prisão perpétua } \\
\text { - Penas longas de prisão }\end{array}$ \\
\hline 5. Regime penitenciário & $\begin{array}{l}\text { - Condições da vida na prisão } \\
\text { - Respeito aos direitos do preso } \\
\text { - Liberdade condicional }\end{array}$ \\
\hline 6. Internações de segurança & $\begin{array}{l}\text { - Internação após cumprimento da pena } \\
\text { - Prisão preventiva }\end{array}$ \\
\hline $\begin{array}{l}\text { 7. Status legal e social de } \\
\text { delinquentes e ex-delinquentes }\end{array}$ & $\begin{array}{l}\text { - Privação de direitos de participação política } \\
\text { - Privação de outros direitos civis } \\
\text { - Recursos sociais acessíveis }\end{array}$ \\
\hline 8. Registros pliciais e penais & $\begin{array}{l}\text { - Expansão e acessibilidade aos registros } \\
\text { - Paradeiro de ex-delinquentes }\end{array}$ \\
\hline 9. Direito penal juvenil & $\begin{array}{l}\text { - Limite de idade } \\
\text { - Tratamento diferenciado ao dos adultos }\end{array}$ \\
\hline
\end{tabular}

Fonte: Os autores.

Nota: A partir de Díez Ripollés (2013). 
A segunda hipótese do autor propóe que os dois modelos político-criminais paradigmáticos e mais opostos quanto aos seus efeitos de inclusão ou exclusão social podem ser representados, no início do século XXI, dentre os países ocidentais, pelos Estados Unidos da América (sistema federal e sistema da maioria de seus Estados federados), de um lado, e pelos países nórdicos europeus (Dinamarca, Finlândia, Noruega e Suécia), de outro.

Nesse sentido, o sistema de controle penal americano constitui, para o autor, o modelo político-criminal ocidental "mais energicamente inspirado na exclusão social dos suspeitos e delinquentes" (DÍEZ RIPOLLÉS, 2013, p. 155, tradução dos autores). Enquanto que os países nórdicos europeus são os que possuem modelo político-criminal "mais decididamente focado na inclusão social dos suspeitos e delinquentes" (DÍEZ RIPOLLÉS, 2013, p. 155, tradução dos autores).

O que é interessante destacar nesse aspecto é que, apesar de estarem em polos contrapostos atualmente, ambos os países compartilharam, durante várias décadas da segunda metade do século XX, um mesmo modelo de intervenção penal: o ressocializador. Foi a partir dos anos 80 do século passado que começou a surgir essa divergência progressiva (DÍEZ RIPOLLÉS, 2013).

Daí a relevância de se proceder a um estudo comparativo, pois permite perceber com clareza empírica que as escolhas de intervenção penal não são naturais e inevitáveis, mas escolhas políticas com determinadas finalidades.

Enfim, a pretensão de Díez Ripollés é fornecer essa proposta de estudo comparativo, para que se possa, a partir de investigaçóes paralelas de aplicação do modelo analítico e tipológico proposto, medir a intensidade de inclusão social ou exclusão social operada pelas políticas criminais dos países.

\section{Conclusões}

Como apontado tanto por David Garland quanto por José Luís Díez Ripollés, os Estados passam, hoje, pela adequação das políticas criminais às transformaçóes sociais desencadeadas pelo advento da pós-modernidade. As políticas modificam a forma com que as instituiçóes e organizaçóes pensam o crime, a pena, a justiça e o controle.

Entretanto, pelo que diagnosticam ambos os autores trabalhados neste artigo, as respostas políticas náo decorrem propriamente das crescentes taxas de criminalidade ou pela descrença no previdenciarismo ou correcionalismo penal. Em lugar disso, as respostas decorrem, muito mais, de condiçóes culturais e criminológicas da pós-modernidade, tais como a insegurança social e abandono do Estado de bem-estar.

Resulta necessário, então, analisar as atuais estruturas dos campos de controle do crime, de modo a revelar suas tendências e seus efeitos. Uma das formas de analisar política 
criminal é a abordagem comparativa, seja entre diferentes países, seja um mesmo país no decorrer do tempo. A abordagem comparativa permite visualizar e demonstrar que não há só um tipo de resposta para o controle do crime, há várias possibilidades, e as escolhas são políticas.

Dentre as análises comparativas, destaca-se, aqui, as desenvolvidas por David Garland e por José Luis Díez Ripollés. Garland analisa as políticas criminais de EUA e Grã -Bretanha no decorrer do tempo, isto é, do final do século XIX até a atualidade. Segundo seu estudo, pode-se dividir este período em modernidade penal (final do século XIX até 1970) e pós-modernidade penal (1980 até a atualidade). À modernidade penal corresponde um paradigma político-criminal, denominado pelo autor como "previdenciarismo penal", o qual ruiu, dando lugar, no período seguinte, ao que o autor denominou de "populismo punitivo".

O populismo punitivo configura-se a partir de um dilema político que surge a partir da década de 1970: uma concepçáo difundida de que há altas taxas de criminalidade e de que o Estado e sua justiça criminal não conseguem prevenir e reprimir essa criminalidade. A partir desse dilema é que as respostas do crime tem sido configuradas.

Segundo Garland, as respostas podem ser de três ordens: adaptativas, quando se adotam medidas que têm por finalidade adaptar as políticas ou a justiça criminal de modo a dotá-las de maior efetividade para a prevenção e persecução penal; denegatórias, aquelas que negam o dilema e reafirmam o velho mito do Estado soberano e seu poder punitivo pleno; e, as simbólicas, que são instrumentais, instituídas para simbolizar que algo está sendo feito, quando, na verdade, sua efetividade é bastante duvidosa para atender aos fins a que se propóe.

A hipótese de Garland é de que as respostas denegatórias e simbólicas são as mais presentes e recorrentes não só nos EUA e na Grã-Bretanha, mas em todos os países ocidentais, configurando o populismo punitivo como um tendência ocidental. O que ocorre apesar do diagnóstico de que as respostas de adaptação, comparadas com soluçóes penais, são mais realistas quanto aos limites do Estado soberano e do seu sistema penal e menos suscetíveis a reforças as divisóes sociais existentes (GARLAND, 2008).

José Luis Díez Ripollés contesta a conclusão de que há uma tendência generalizada ao populismo punitivo no mundo ocidental e propóe outro modelo de análise políticocriminal. Esse modelo abandona as categorias "punitivismo" e "moderação" e cria outras: política criminal "inclusiva socialmente" e "exclusiva socialmente”. Segundo o autor, essas categorias funcionam melhor porque o que importa, em última análise, é o efeito social gerado por uma determinada política criminal. Note-se que um Estado pode ter uma política criminal que produza a inclusão social dos suspeitos e condenados e, por outro lado, possuir uma série de leis que criminalizem novas condutas. Dizer tão somente que 
esse Estado adota uma política criminal punitiva, não retrataria com fidelidade a realidade deste lugar. Da mesma forma, um Estado pode ter pouquíssimos crimes tipificados em seu ordenamento, mas, por outro lado, não respeitar garantias individuais dos cidadãos, tais como devido processo legal, presunção de inocência, entre outros.

A ideia de Díez Ripollés é construir uma linha comparativa em que, em um polo, teríamos um Estado com a política criminal mais inclusiva socialmente, e em outro polo, o Estado com a política criminal mais exclusiva socialmente. Para determinar se um país está mais perto da inclusão social ou da exclusão, o autor ressalta que se tem que identificar determinadas regras e práticas penais, de modo a aferir seus efeitos sobre as pessoas envolvidas. Para tanto, ele elenca vinte e cinco indicadores a serem analisados, os quais referem-se a: controle de espaços públicos, garantias penais, sistema de determinação da pena, penas máximas, regime penitenciário, internaçóes de segurança, status legal e social de delinquentes e ex-delinquentes, registros policiais e penais e direito penal juvenil.

Além dos indicadores, Díez Ripollés sugere quais são os países-paradigmas de cada um dos polos no início do século XXI. Isto é, para o autor, o sistema de controle penal dos EUA constitui o modelo político-criminal ocidental mais inspirado na exclusão social como solução para o crime; e, na outra ponta, estariam os países nórdicos europeus que, na hipótese do autor, são os que possuem o modelo político-criminal mais focado na inclusão social dos envolvidos.

Interessante notar — o que destaca, mais uma vez, a importância de análises rigorosas e comparativas de políticas criminais - que, apesar desses dois países estarem em polos opostos atualmente, essa situação nem sempre foi assim. Ambos os países compartilharam, durante o século XX, um mesmo modelo de intervenção penal, o ressocializador, tendo se diversificado a partir de 1980.

Isso demonstra, de novo, que as respostas dadas pelos Estados para o controle do crime não passam de escolhas políticas, restando aos pesquisadores que forneçam o maior número de informaçóes qualificadas e embasadas empiricamente, de modo a influenciar para a adoção de políticas criminais democráticas, inclusivas e efetivas.

\section{Referências}

DÍEZ RIPOLLÉS, José Luis. Politica Criminal y Derecho penal. 2a . ed. Valencia: Tirant lo Blanch, 2013.

GARCÍA-PABLOS DE MOLINA, Antonio. Criminologia: introdução a seus fundamentos teóricos. 5. ed. rev. e atual. São Paulo: RT, 2006.

GARLAND, David. A cultura do controle: Crime e ordem social na sociedade contemporânea. Tradução de André Nascimento. Rio de Janeiro: Revan, 2008. 
MASIERO, Clara Moura; CHIES-SANTOS, Mariana. “'De volta para o passado': políticas criminais e de segurança pública no Brasil da ditadura militar à República atual”. In: CONPEDI/UFSC (org.). ANDRADE, Vera Regina Pereira de; ÁVILA, Gustavo Noronha de; CARVALHO, Gisele Mendes de. (coord.). Criminologias e politica criminal. Florianópolis: CONPEDI, 2014, p. 530-558. 